\title{
Um Salto na Rede - Fronteiras e transições da Crítica Cultural Contemporânea num Contexto Mediático em Mudança
}

\author{
A Leap in the Network - Frontiers and Transitions of \\ Contemporary Cultural Criticism \\ in a Context Changing Media
}

Celso Martins - Escola Superior de Artes e Design - IPLeiria c.cruzmartins@gmail.com https://doi.org/10.26619/978-989-9002-14-2.2

\begin{tabular}{|c|c|c|}
\hline Recebido / Received & Aceite / Accepted & Publicado / Published \\
15.06 .2020 & 24.06 .2020 & 15.01 .2021 \\
\hline
\end{tabular}

Como citar este capítulo / How to quote this chapter:

Martins, C. (2021). "Um Salto na Rede - Fronteiras e transições da Crítica Cultural Contemporânea num Contexto Mediático em Mudança". In Lourenço, J. \& P. Lopes (eds.), Comunicação, Cultura e Jornalismo Cultural (pp. 36-50). Lisboa: NIP-C@M \& UAL, disponível em https://repositorio.ual.pt/handle/11144/4749 DOI https://doi.org/10.26619/978-989-9002-14-2.2 


\section{Resumo}

Gerada nas fundações da própria modernidade, a imprensa foi desde o início uma das traves mestras dessa mesma modernidade na medida em que the coube assegurar a coesão da comunidade urbana, a possibilidade de opinião pública, o exercício da preposição e divergência crítica.

Ao mesmo tempo, ela ajudava a definir a cultura formal e a criação artística como um espaço de emancipação que procurava resistir aos aspetos mais formatadores do mundo moderno, como o enquadramento de massas, a alienação, a mercantilização cultural e a confusão entre arte (associada à fruição) e o entretenimento (estreitamente ligado ao consumo). Estaremos já longe dos diagnósticos feitos por Theodor Adorno e Walter Benjamin sobre a sociedade de massas e das suas conclusões sobre a produção e o consumo cultural, mas independentemente do nosso posicionamento sobre 0 estado da modernidade (inconclusa, concluída historicamente ultrapassada ou destruída) sabemos que o estatuto, o espaço, as condições e a metodologia da crítica cultural se metamorfoseou profundamente no contexto mediático contemporâneo, que é híbrido, fragmentário, desierarquizado e tecnologicamente descontínuo.

Nesse contexto, que ajuda a dissolver fronteiras entre as diferentes vocações que tradicionalmente eram atribuídas a jornais, revistas, magazines culturais televisivos ou radiofónicos, como a informação pública, social, política, cultural e artística, e a sua digestão crítica, este ensaio pretende ser uma reflexão sobre a crise de identidade da crítica cultural, suas causas, desafios que enfrenta e as alternativas que se lhe colocam. 


\section{Abstract}

Generated in the foundations of modernity itself, the press was from the beginning one of the master beams of this same modernity to the extent that it was up to it to ensure the cohesion of the urban community, the possibility of public opinion, the exercise of preposition and critical divergence.

At the same time, it helped to define formal culture and artistic creation as a space of emancipation that sought to resist the most formatting aspects of the modern world, such as mass framing, alienation, cultural mercantilization and the confusion between art (associated with fruition) and entertainment (closely linked to consumption).

We will be far from the diagnoses made by Theodor Adorno and Walter Benjamin on mass society and its conclusions on the production and cultural consumption, but Regardless of our position on the state of modernity (inconclusive, historically completed or destroyed) we know that the status, space, conditions and methodology of cultural criticism has morphed deeply into the contemporary media context, which is hybrid, fragmentary, desierarquizado and technologically discontinuous. In this context, which helps to dissolve boundaries between the different vocations that were traditionally attributed to newspapers, magazines, television or radio cultural magazines, such as public, social, political, cultural and artistic information, and its critical digestion, this essay aims to be a reflection on the identity crisis of cultural criticism, its causes, challenges it faces and the alternatives that arise to it. 


\section{Apresentação}

A crítica de arte nasceu sob o signo da velocidade moderna, do shock, o contacto intenso e efémero com as obras de que, no século XIX, falava já Baudelaire, um dos primeiros críticos de arte (Baudelaire, 1993). Essa negociação com o tempo nunca abandonou a sua matriz. Mais do que escrutinar as diversas tendências teóricas da crítica cultural das últimas décadas, neste ensaio tentaremos analisar como a experiência do tempo e das diferentes sedes institucionais e tecnológicas que a crítica encontrou a definiram desde as origens ao momento atual.

\section{A crítica cultural como produto e alicerce da mo- dernidade}

Por vezes, tendemos a esquecer que arte é uma coisa infinitamente mais antiga do que a crítica de arte que, embora a arte não possa existir sem um pensamento, viveu muito tempo sem esse mecanismo de receção. Na verdade, a crítica e o crítico como categoria para-profissional, são a resposta a todo um mundo artístico novo, começado a erigir no século XVII quando o essencial das peças institucionais e públicas do sistema artístico moderno principiaram a encaixar-se.

Depois da criação, por Luis XIV, da Academia Real das Artes (1648), com seus mestres e alunos, os seus salões que rapida-

mente se tornaram públicos, oferecendo para além do esplendor do poder do estado também uma política do gosto, o campo 
só ficaria completo com dois outros agentes decisivos: o marchand, que associava a produção artística à existência de um mercado de arte, e o crítico, a figura que the assegurava legitimidade simbólica e que ligava este mundo a um outro também emergente: o da imprensa.

O carácter mais transversalmente público das artes e a imprensa urbana são, pois, duas traves mestras do campo artístico que se vai alargar primeiro sob a égide cultural do iluminismo, mas acompanhando, depois, todos os debates políticos e estéticos do século XIX, do romantismo e realismo aos alvores das vanguardas artísticas.

O caráter urbano do campo artístico e o espaço de dissensão que nele se projeta através dos jornais é, em grande medida, um reflexo do triunfo dos regimes liberais em boa parte dos países europeus que criaram aquilo a que o filósofo Jurgen Habermas definiu como a esfera pública literária (Habermas, 1962) e que foi convertida conceptualmente por outros autores (McGuigan, 2005) no que hoje podemos chamar, mais abrangentemente, a esfera pública cultural.

É aí que se engendra a figura do publicista, de que inicialmente, o crítico é uma subcategoria, simultaneamente independente da academia e do mercado e por isso capaz de estabelecer cumplicidades com os artistas mais desalinhados e inconformistas, mas ao mesmo tempo, é nesse ambiente liberal, por vezes revolucionário, que a arte começa a ser pensada como parte integrante de um projeto mais alargado de emancipação da humanidade. 


\section{Da modernidade à massificação}

É, em traços largos, este o perfil do iluminista Denis Diderot (1713-1784), um dos primeiros críticos de arte mas, também, sensivelmente, o de trotskista Clement Greenberg (1909-1994), o mais influente crítico de arte americano do século XX, que em 1939 publicou na revista Partisan Review o texto "Avant-Garde and Kitsch" (Greenberg, 1939), bem significativo do sentimento de perda da influência das elites sobre o consumo cultural dos grandes públicos que havia sido a norma até então.

Aquilo que, nesse texto, Greenberg designa por Kitsch e que nas suas palavras corresponde a um processo de "falsificação cultural" é, posto em termos menos moralizantes, o resultado da industrialização no campo da cultura que encontrou novas formas de produção (o múltiplo fotográfico ou cinematográfico, por ex.) e de difusão (as revistas e jornais de grande tiragem, os teatros 'comerciais', os cinemas) que resultam numa radical ampliação e transformação do mercado cultural e que vinham baralhar dicotomias anteriormente bem demarcadas, que colocavam de um lado a arte 'séria' dos museus, dos concertos de música erudita ou dos romances e poesia modernistas, e do outro, a cultura 'média' e o entretenimento.

Como consequência desses processos de recomposição cultural, hierarquias como alta/baixa cultura e 'belas artes'/cultura popular foram sujeitas, no novo contexto massificado, a uma pressão que denunciava a 'superioridade' estética e sofisticação cultural 
das elites enquanto reflexo ou manifestação de privilégio social e dominação cultural, o que atingiu não apenas o estatuto desses produtos artísticos como o dos seus comentadores. Nem sempre essas transformações foram vistas de modo negativo. Lawrence Alloway, o crítico inglês que primeiro usou a palavra "pop" para designar manifestação artísticas que se associavam a referências do quotidiano e ao consumo, via nelas um potencial libertador que estava longe de ser estéril (Alloway, 1958).

Se a crise da crítica tem razões artísticas, como a que se precipita com a mudança no paradigma da arte contemporânea, no final dos anos 60, que através das neo-vanguardas vem desvalorizar a dimensão estética da arte, ela deve ser entendida também, sobretudo a partir do pós II Guerra Mundial, no contexto de uma época histórica particularmente próspera que gerou uma revolução tecnológica nos mais variados campos da vida material e uma revolução mediática, que generalizou e diversificou no ocidente meios de comunicação de alcance abrangente, com particular destaque para a televisão que passa a ser o principal orgão de mediação e auto-percepção social. Este novo contexto de mimetização especular e de indução de modelos de consumo não é exclusivamente televisivo e, viu crescer nos jornais e revistas, zonas associadas ao divertimento e à informação cultural ligeira como o "lifestyling".

A cultura de massas criou, pois, um sistema que, simultaneamente, cobria as necessidades de entretenimento de uma população indissociada e desenraizada culturalmente e um "star 
system" que lhe oferecia um panteão de deuses efémeros, sempre renováveis e transitórios.

Estas transformações não significaram necessariamente uma diminuição do espaço dedicado à cultura formal nos jornais (Heikkilä, R., Lauronen, T. \& Purhonen, S., 2018), mas encorajaram um tipo de abordagem dos objetos culturais que desvaloriza os mecanismos críticos e valoriza a promoção e a divulgação.

O lugar da crítica enquanto resposta a uma produção formal não estereotipada e tida como mais exigente, na medida em que pedia ao leitor um background cultural prévio, foi significativamente secundarizado no espaço dos jornais, ao mesmo tempo que a sua dissociação com a cultura da 'sociedade do espectáculo' (Debord, 1967) ia fazendo novos caminhos críticos. Como já se tinha tornado claro desde os alvores da escola de Frankfurt, a questão da crítica é sempre, no limite, uma questão política.

\section{Entre o blog e a bienal: abalos e desafios da crítica cultural numa paisagem comunicacional fragmentada}

Vários fenómenos e alterações estruturais fazem com que pensemos a questão do lugar da crítica nos primeiros anos do milénio para além do horizonte tradicional da sociedade de massas. Por um lado, se a própria lógica do consumo (económico, cultural, simbólico) conhece intensos processos de massificação, a viragem do milénio revela tendências culturais contraditórias que combinam aspectos de homogeneização com erupções lo- 
cais ou culturalmente específicas no quadro da globalização. No campo artístico esse é o tempo da multiplicação de bienais um pouco por todos os continentes e de uma reivindicação de especificidade identitária, nomeadamente da arte não ocidental, mas também associada a grupos específicos como as mulheres e as minorias étnicas que pressionam as hegemonias tradicionalmente ocidentais e os modelos, e genealogias críticas que as sustentam.

Mas essa 'bienalização' não transportou apenas preposições descolonizantes, em muitos casos ela manteve intactas as relações entre os centros (Nova lorque, Berlim, Londres, etc.) e as periferias, ainda que tenha aberto os primeiros a novas latitudes. $O$ forte interesse pela arte africana ou asiática nos primeiros anos do milénio é um exemplo desse mecanismo.

Ao mesmo tempo, há que lembrar que a intensificação da globalização favoreceu ainda um processo de espectacularização do próprio campo artístico associado ao turismo cultural. Essa espécie de apoteose da indústria da cultura conhece talvez no museu o seu mais evidente emblema. Como lembra Claire Bishop,

"Looking at this global panorama of contemporary art museums, what binds them all together is less a concern for a collection, a history, a position, or a mission than a sense that contemporaneity is being staged on the level of image: the new, the cool, the photogenic, the well-designed, the economically successful” (Bishop, 2013). 
A essa construção arquitetónica e institucional corresponde uma rede de programadores e curadores que coteja os artistas e os integra em exposições, agiliza relações com os decisores institucionais, o mercado galerístico e o colecionismo no interior de um sistema que faz sobrepor as dimensões crítica e curatorial na figura do comissário. Neste contexto, o ponto de vista tendencialmente exterior do crítico tradicional, associado à imprensa, é demasiadas vezes visto como descartável ou mesmo contraproducente.

Mas nenhuma outra transformação estrutural foi recentemente tão revolucionária como o aparecimento da internet. Criada no final dos anos 80, a World Wide Web transfigurou todos os nossos processos socioculturais. Das comunicações com o estado, aos modos de trabalho, dos consumos materiais às ações políticas, a rede redefiniu, desmaterializando e ligando indefinidamente todos com todos, o que outrora entendíamos como esfera pública. A produção e receção cultural não ficou nem poderia ficar de fora deste processo total. Foi, aliás, dos campos onde mais metamorfoses operou. Uma das mais decisivas foi a dissipação de uma fronteira clara entre produtores e destinatários de conteúdos. Fazendo com que todos sejam, potencialmente, criadores e divulgadores de imagens, de textos e de ligações, ela colocou a interatividade no centro da nossa cultura.

Com isso, o cenário orweliano de uma sociedade hipnotizada a partir de um número limitado de centros (políticos, económicos ou religiosos) deu lugar a um mundo em rede, tendencialmente rizomático, sem hierarquia aparente, que empresta a cada in- 
divíduo uma, por vezes, ilusória sensação de soberania e participação individual. No campo da criação e crítica artísticas, a chegada da internet veio ao encontro de processos de interação e redefinição editorial que estavam já em incubação a partir do final dos anos 60 , nomeadamente, no seio de comunidades como o movimento international Fluxus que usava o correio para trocar ideias sobre arte ou instruções para performances.

O crítico Jerry Saltz é normalmente apontado como um pioneiro na crítica de arte online, pela sua utilização precoce do Twitter e do Facebook, mas como explica Charlotte Frost (Frost, 2019), ele é antecipado por uma série de plataformas como a ARTEX, ACEN, fAf, LEA ou a Matrix que geraram novas formas de relacionamento entre o discurso dos artistas e dos críticos, abrigando preposições artísticas, conferências e intercâmbios electrónicos transcontinentais.

Hoje a paisagem de produção artística e de comentário sobre arte é composta por uma infinidade de blogs, sites pessoais ou coletivos, páginas de Facebook, Twitter ou Instagram, revistas especializadas, fóruns de discussão temáticos, ao mesmo tempo que a rede permitiu a uma infinidade de instituições museológicas, académicas ou sites memoriais de artistas colocarem os seus arquivos online.

Estas novas condições cibernéticas vieram alterar profundamente as nossas relações com a informação na medida em que a rede se constitui num enorme (infinito?) arquivo de informa- 
ção sobre o presente e sobre o passado, o que produz inevitavelmente um efeito na perceção da profundidade histórica com que se olha para uma obra ou uma trajetória artística, mas também na experiência da temporalidade, ela própria, tão decisiva na possibilidade de a arte e a crítica participarem num projeto de transfiguração cultural.

Estamos longe de ver concluído este processo de reconfiguração tecnológica que nos vai levar decididamente do jornal ou revista em papel para outros dispositivos com todas as consequências comunicacionais e culturais que essa transformação implica. Convém, não esquecer, que esse parto não está concluído e não está a acontecer sem perdas, na medida em que corresponde, igualmente, a uma reconversão económica. E também essas condições se ligam ao destino da crítica cultural.

A grande dificuldade revelada pela imprensa escrita em adaptar-se a uma nova ecologia informativa precipitou a imprensa numa crise de conversão com impactos financeiros muito sensíveis no número de leitores e na oferta de publicidade.

Uma das consequências dessa reconversão passou pela paulatina desprofissionalização da crítica cultural. A partir da última década, uma parte dos jornais deixou de remunerar os conteúdos de crítica cultural que publica, ou passou a remunerá-los a valores bastante inferiores. Os críticos "residentes" foram em grande medida substituídos por jornalistas generalistas que também cobrem os eventos culturais, ou por académicos, figu- 
ras institucionais ou aspirantes a lugares de decisão na indústria cultural que cedem pontualmente a sua propriedade intelectual a troco de visibilidade pública. Não é difícil de imaginar a distorção exercida por este mecanismo na receção valorativa dos objetos culturais e o viés corporativo daí resultante.

Esse processo de empobrecimento dos jornais, que tem uma componente de desqualificação e de perda de independência às mãos do soundbyte e da reação imediata à realidade mais contingente, tem um preço político (as fake news, o populismo, a ausência de nuance na informação e na opinião) e cultural (a diminuição do espaço dedicado à reflexão e a sua consequente descaracterização): e pode conduzir à submersão dos média tradicionais num indissociado oceano digital. Sobrevoando tudo isto, temos o algoritmo que faz com que cada escolha, cada abertura de página ou "like" que colocamos numa imagem ou 'post' numa rede social nos reconduza às nossas escolhas, nos confirme cultural, política e esteticamente. Esse efeito especular é não apenas uma perversão potencial das expectativas democratizantes, muito justamente associadas ao mundo digital como significativamente, o oposto da crítica que deve gerar diferença, descentramento e desconformidade.

\section{Conclusão}

Iniciámos este ensaio dizendo que a arte é muito mais antiga do que a crítica. De igual modo, pode dizer-se com confiança que ambas sobreviverão ao novo sistema mediático e à sua natureza fragmentária e desierarquizada. 
O século XXI foi banhado por uma revolução tecnológica com amplos efeitos na produção de subjetividade e na natureza dos encontros e conflitos culturais, com aspetos francamente democratizantes, gerando mais vozes e mais sedes discursivas, ainda que, esse panorama nos pareça exponencialmente mais confuso. Não é indiferente se se escreve num jornal, numa revista especializada, num blog ou numa plataforma digital, se se escreve para um público generalista ou específico, se se é pago por isso ou não. Como não é indiferente o modo como se lê e o enquadramento tecnológico e simbólico da própria leitura. Todos estes fatores são normalmente invisíveis nos edifícios teóricos que sustentam a crítica mas têm um impacto indelével no discurso que ela produz.

\section{Bibliografia}

Alloway, L. (1958). The Arts and the Mass Media, Londres: Architectural Design.

Baudelaire, C. (1993). O Pintor da Vida Moderna. Lisboa: Vega.

Bishop, C. (2013). Radical Museology, or, What's Contemporary in Museums of Contemporary Art?. London: Koenig Books.

Debord, G. (1967). La Societé du Spectacle. Paris: Éditions BuchetChastel.

Frost, C. (2019). "Digital Critics: The Early History of Online Art Criticism", Leonardo, Volume 52, Issue 1, February 2019, pp.37-43. 
Greenberg, C. (1939). "Avant Garde and Kitsch". The Partisan Review, pp. 34-49.

Habermas, Jürgen. (1962 trans 1989). The Structural Transformation of the Public Sphere: An Inquiry into a category of Bourgeois Society. Cambridge: Polity.

Heikkilä, R., Lauronen, T., \& Purhonen, S. (2018). "The crisis of cultural journalism revisited: The space and place of culture in quality European newspapers from 1960 to 2010.", in European Journal of Cultural Studies, 21(6), pp.669-686, available in: https://doi. org/10.1177/1367549416682970.

McGuigan, J. (2005). The cultural public sphere. Londres: Loughborough University. 